\title{
Combined TOPEX/Poseidon TEC and ionosonde observations of negative low-latitude ionospheric storms
}

\author{
K. J. W. Lynn ${ }^{1}$, M. Sjarifudin ${ }^{2}$, T. J. Harris ${ }^{3}$, and M. Le Huy ${ }^{4}$ \\ ${ }^{1}$ Ionospheric Systems Research, 38, Goodchap St., Noosaville, 4566, Australia \\ ${ }^{2}$ National Institute for Aeronautics and Space, LAPAN, Jl. Dr. Junjunan No. 133, Bandung 40173, Indonesia \\ ${ }^{3}$ Intelligence, Surveillance and Reconnaissance Division, Defence Science and Technology Organisation, PO Box 1500 , \\ Edinburgh, 5111, Australia \\ ${ }^{4}$ Hanoi Institute of Geophysics, NCST of Vietnam, 18 Hoang Quoc Viet St., Cau Giay, Hanoi, Vietnam
}

Received: 28 April 2004 - Accepted: 18 May 2004 - Published: 7 September 2004

\begin{abstract}
Ionospheric storms showing a strong depression in daytime $f o \mathrm{~F} 2$ values were sought which penetrated to lowlatitudes, as identified by vertical ionosondes operating at Darwin and Townsville over the period 1992-1998. The 32 storms thus identified showed a seasonal occurrence peaking near the equinoxes with a bias to the summer side. Of these storms, three (27 March 1995, 25 October 1997, 8 November 1997) combined Australian and South East Asian ionosonde observations with local afternoon TOPEX/Poseidon measurements of TEC. The equatorial anomaly is usually well developed at this time of day and consequently these storms were chosen for detailed study. The TOPEX/Poseidon satellite provided vertical profiles of the ionosphere across both hemispheres, thus allowing the totality of storm behaviour to be observed for the first time at low-latitudes and related directly to the ionosonde observations. The three storms were remarkably consistent in their behaviour, the negative ionospheric storm day followed some 24-36 h after the beginning of a magnetic storm and the development of the equatorial anomaly was suppressed. However, the suppression of the equatorial anomaly was not the main cause of the strong depression in $f o \mathrm{~F} 2$ observed by the Southern Hemisphere ionosondes. The latter was associated with an additional bite-out in both TEC and $f o \mathrm{~F} 2$ that occurred on the southern side of the magnetic equator. None of the three storms produced any major negative disturbance outside the range of normal variability of TEC and $f o \mathrm{~F} 2$ at the northern latitude sites for which data was available, despite the absence of the anomaly. The satellite measurements show the strength of the anomaly to be highly variable from day-today and anomaly peaks are frequently not present even on magnetically quiet days. Thus, an absence of anomaly peaks is contained within the normal variability of non-storm days. The north-south asymmetry and seasonal occurrence are consistent with an enhancement of the normal summer-to-winter system carrying compositional changes induced by energy
\end{abstract}

Correspondence to: K. J. W. Lynn

(kenlynn@nbcnet.com.au) inputs at auroral latitudes to equatorial latitudes not usually reached. The ability of associated atmospheric and/or electric field changes to coincidentally switch off the equatorial E region electrojet remains to be explained, as indeed does the large range of variability in equatorial anomaly development from day-to-day evident in the TEC measurements outside periods of geomagnetic disturbance. Some possible positive storm effects occurring on the day preceding the negative storm phase are also noted.

Key words. Ionosphere (Equatorial ionosphere; Ionospheric disturbances) - Magnetospheric physics (Storms and substorms)

\section{Introduction}

Major disturbances in the solar wind impacting the Earth's magnetosphere result in magnetic storms as observed by ground-based magnetometers. At any given location, an ionospheric storm often accompanies the magnetic storm. The ionospheric storm is characterized by whether the major effect is either a reduction (negative storm) or an increase (positive storm) in ionospheric electron density (see reviews by Fuller-Rowell and Codrescu, 1997; Prölss, 1997; Buonsanto, 1999; Richmond and Lu, 2000; Danilov, 2001). The relationship between a magnetic storm and any associated ionospheric disturbance is complex and varies with geographic location. Thus, ionosondes at different latitudes and longitudes may see a depression, an enhancement, a combination of both, or no recognizable effect in $f o \mathrm{~F} 2$ during the period of any particular magnetic storm (Prölss, 1993; FullerRowell and Codrescu, 1997; Szuszczewiez et al., 1998). General reviews of $\mathrm{F} 2$ region dynamics have been given by Rishbeth $(1998,2000)$.

Negative ionospheric storms, as seen at high and middle latitudes, are believed to be caused by auroral zone thermospheric heating during the main phase of the magnetic storm. This heating alters the ratio of atomic oxygen relative to 
molecular nitrogen at ionospheric heights by atmospheric upwelling. Such compositional change, in turn, produces an increase in the electron recombination rate resulting in reduced electron densities in the $\mathrm{F} 2$ region of the ionosphere. The auroral zone heating produces an equatorward wind which carries the compositional changes to lower latitudes. Clear evidence of such changes reaching the equatorial zone has been lacking. Under undisturbed conditions, the low-latitude ionosphere is dominated by the effects of equatorial electric fields developed by winds blowing across the Earth's magnetic field. The resultant $\boldsymbol{E} \times \boldsymbol{B}$ force acting on ionization produces an upward force (often referred to as the fountain effect). The uplifted ionization diffuses down the field lines to form the equatorial anomaly in electron density whose southern peak sits over Indonesia. The electric field also produces the equatorial electrojet, a current flowing mainly at $\mathrm{E}$ region heights along the magnetic equator. The eastward electrojet current and hence the electric field has been observed to cease and even reverse in association with magnetic storms. The subsequent failure of the equatorial anomaly to develop, as suggested by Sastri, 1988; Mikhailov, 1996, could result in a reduction in electron density at equatorial anomaly latitudes. The relative importance of these and other low-latitude disturbance mechanisms associated with magnetic storms has not been clear (Richmond and $\mathrm{Lu}, 2000$ ). Some papers specifically describing a variety of ionospheric storm effects at low-latitudes in the South-East Asian and Australian sector have been given by Tanaka (1981), Huang and Chen (1985), Huang and Chen (1991), Ma et al., (1995), Wilkinson (1995).

This paper examines the occurrence and characteristics of negative ionospheric storms observed at low-latitudes and South East Asian longitudes. Total Electron Content (TEC) profiles obtained from the TOPEX/Poseidon satellite provided direct observation of ionospheric storm behaviour simultaneously in both hemispheres. Such behaviour could only be inferred previously from data limited in geographic extent. The latitudinal TEC profiles allowed the relative importance of the cessation of the equatorial anomaly and the penetration of compositional change to be determined. The longitudinal spread of ionosondes provided verification of the large-scale nature of the events.

Low-latitude storms are defined here as those producing major all-daytime depressions in $f o \mathrm{~F} 2$ at Darwin and Townsville. These sites lie on the outer slope of the southern equatorial anomaly peak. Experience has shown that the effect of such storms is evident some distance northward into the equatorial anomaly zone. Although referred to here as low-latitude ionospheric storms, these storms are merely the low-latitude component of negative ionospheric storm events which extend south from the auroral zone in the hemisphere of observation. This will be evident in the results presented. Three major low-latitude storms, for which both ionosonde and TOPEX/Poseidon TEC observations were available, are examined in detail.

\section{Data sources}

Vertical ionosonde data was obtained from Kel IPS71 ionosondes at Phu Thuy (Hanoi Institute of Geophysics, Vietnam) and Sumedang (The National Institute for Aeronautics and Space, Indonesia, LAPAN), a Defence Science and Technology Organisation (DSTO, Australia) ionosonde at Darwin and IPS41 ionosondes of the Australian Ionospheric Prediction Service (IPS) at Vanimo and Townsville. The Kel IPS71 and the DSTO ionosondes were capable of receiving oblique FMCW ionosonde transmissions. DSTO FMCW ionosonde transmitters operated at Songkhla, Cocos Island, Darwin, Vanimo and Townsville with DSTO oblique ionosonde receivers at Bangkok, Darwin, Derby and Townsville and the Kel IPS71 ionosonde at Sumedang. Some additional scaled vertical ionosonde data was obtained via the World Data Center from Chung-Li, Kokubunji and Learmonth. All other ionogram scaling was done from the original ionograms at the site ionogram repetition rate to ensure maximum accuracy and the preservation of detail. The location of ionosonde sites, reflection points and oblique paths are shown in Fig. 1.

TOPEX/Poseidon data was obtained on CD-ROM with additional data downloaded from the TOPEX Poseidon Internet data site (see acknowledgements).

The TOPEX-Poseidon satellite makes 254 passes across the geographic equator every 9.9156 days. The 254 passes then repeat exactly in subsequent 9.9156 day periods. The satellite orbit drifts slowly westward in the Sun-Earth frame, taking some 60 days for a 24 -h period to be sampled. The TOPEX TEC measurements are given as a range correction which also includes a bias which is not well defined. In converting to TEC, the bias was obtained experimentally as -5.25 TEC units (TECU) by plotting TEC against $f o \mathrm{~F} 2$ values for satellite passes over Darwin Sumedang and Vanimo.

TOPEX/Poseidon TEC measurements allow a world-wide sampling of variability in the magnitude of the equatorial anomaly as a function of longitude, as well as of ionospheric storm effects. The complication of satellite passes occurring at the same local time but at differing universal times, combined with the limited sampling rate, makes it difficult to unravel the superimposed effects of differing timedependencies without the help of other data sources.

However, TOPEX/Poseidon TEC data does supply an essentially instantaneous cross section of the equatorial anomaly not easily obtained by any other means and is therefore used in this paper.

\section{Negative ionospheric storm occurrence observed at low latitudes}

For the purposes of this paper, negative ionospheric storms observed at low latitudes were identified by examining scaled hourly foF 2 data provided by the Australian Ionospheric Prediction Service from their ionosondes at Darwin and Townsville. The identification of storms to be investigated 


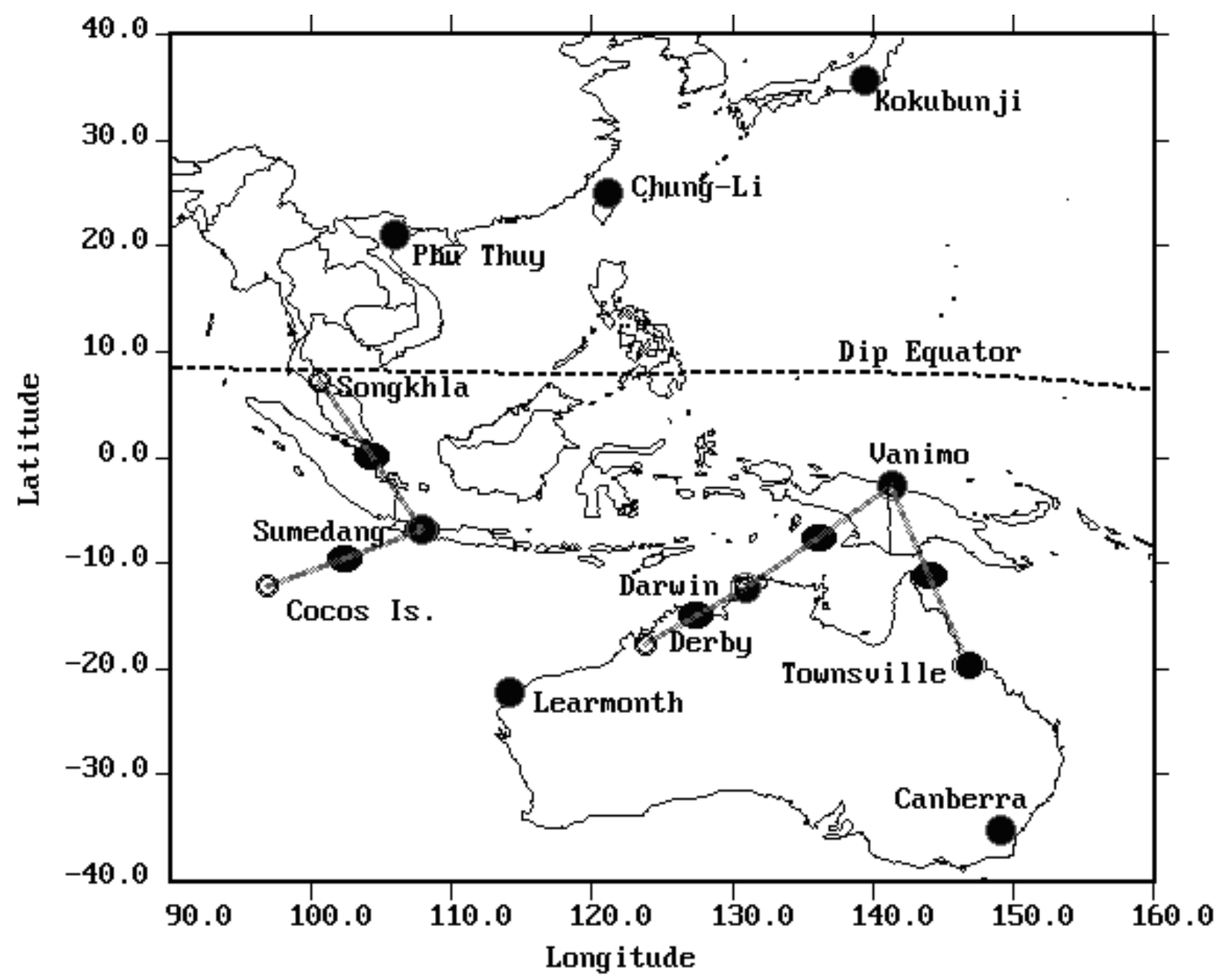

Fig. 1. The location of ionosonde sites and reflection points (filled circle) relative to the magnetic dip equator.

was therefore limited to the southern side of the magnetic equator. Only storms producing a major reduction in F2 critical frequencies at these sites were counted. Such an identification is necessarily subjective and far from complete but is representative of major negative storms at southern equatorial anomaly latitudes. Some 32 storms meeting the above criteria were identified over the period 1992-1998.

The occurrence of these storms (1992-1998) is shown in Fig. 2. Figure 2 also shows the occurrence of magnetic disturbance worldwide over this period as identified by values of the magnetic ring current index $D_{s t}<-40$. The magnetic planetary index for $A_{p}$ values $>25$ is also shown (see Fares Saba et al., 1997 for a discussion of their relationship). Both magnetic disturbance indices exhibit similar equinoctial peaks in occurrence with a bias towards Southern Hemisphere summer. A detailed examination of magnetic and ionospheric storm magnitudes showed little relationship. Indeed, some of the largest magnetic storms occurring over the period of interest produced no evident negative ionospheric storm effects at the latitudes and longitudes considered here. This does not preclude the observation of such effects elsewhere, since such effects are geographically limited in ex- tent. No negative ionospheric storms meeting the identification criteria were identified in 1996 near sunspot minimum. The equinoctial peak in the occurrence of magnetic storms has long been known but causation is still controversial. Recent studies of this variation are given by Clúa de Gonzales et al. (2001), Lyatsky and Tan (2003) and Chen (2004). The results of Figure 2 show that this seasonal relationship continues to hold for the subset of ionospheric storms with negative effect observed here at low latitudes.

\section{Combined TOPEX and ionosonde observations}

Of the 32 low-latitude ionospheric storms identified, only three coincided with afternoon passes of the TOPEX/Poseidon satellite in the South East Asian longitudinal range. Afternoon passes were sought since this is when the daytime equatorial anomaly is normally well developed. Observations of these three storms are described below.

Note that the magnetic equator is approximately $8^{\circ}$ north of the geographic equator at these longitudes (as shown in Fig. 1). 

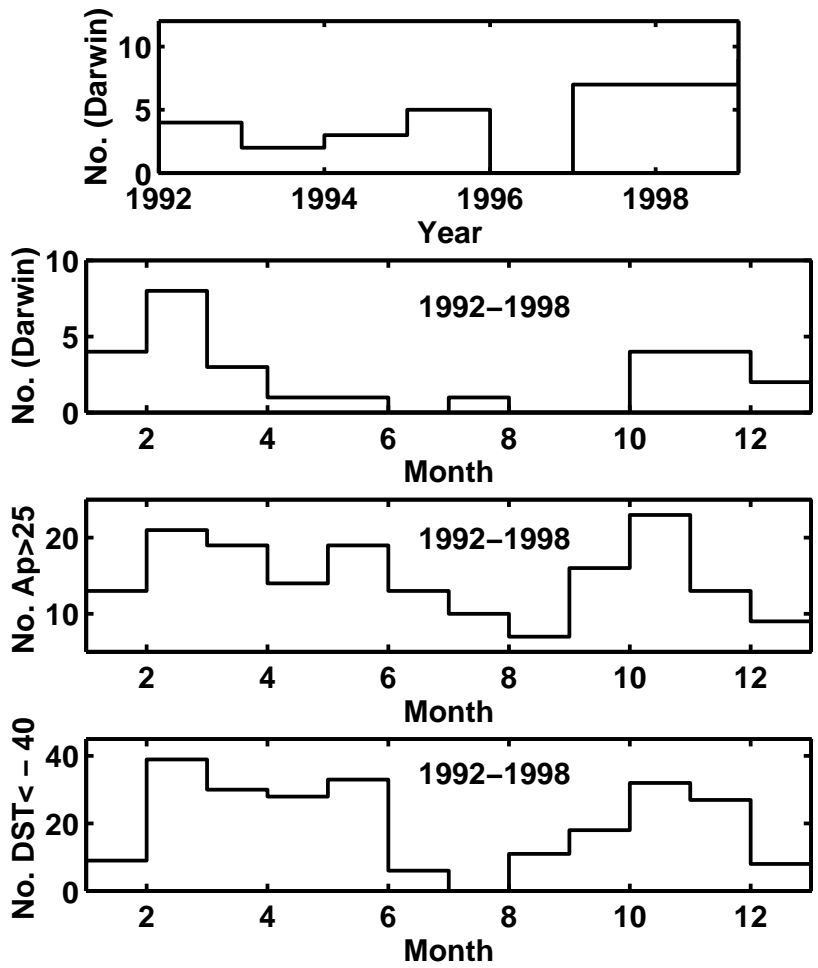

Fig. 2. Ionospheric storm occurrence (Darwin and Townsville) as a function of year and month compared to geomagnetic storm occurrence $\left(A_{p}>25\right.$ and $\left.D_{s t}<-40\right)$ over the period $1992-1998$.

\subsection{Storm 1: 27 March 1995}

Figure 3 provides plots of $f o \mathrm{~F} 2$ for vertical ionosondes or oray F2 maximum observed frequency for oblique paths centered on the storm day as observed at seven ionosonde reflection points within and slightly to the north of Australia. Median values are also provided for comparison. All sites shown in Fig. 3 exhibit a strong depression in maximum F2 frequencies throughout the daylight hours of 27 Mar 1995, extending into the evening. The observations of Fig. 3 cover the longitudinal range $114^{\circ}-144^{\circ}$ and latitudinal range $-2^{\circ}$ to $-7^{\circ}$. The Sumedang ionosonde was not operating on this date.

In Fig. 3, the magnetic disturbance $D_{s t}$ index for the seven-day period is also shown for comparison with the ionosonde data. The negative ionospheric storm is seen to be associated with a magnetic storm commencing near sunrise on the previous day and reaching its peak on the night preceding the day of ionospheric depression.

The vertical line running through Fig. 3 indicates the equator crossing time of the afternoon TOPEX/Poseidon satellite pass at 15:54 LT on the 27 March 1995.

The location of TOPEX satellite passes through the Southeast Asian region and northern Australia are shown in the upper part of Fig. 4, as observed over the eight day period, 24-31 March 1995. The TOPEX pass occurring at the equatorial crossing time of 15:54 LT on 27 March is shown in

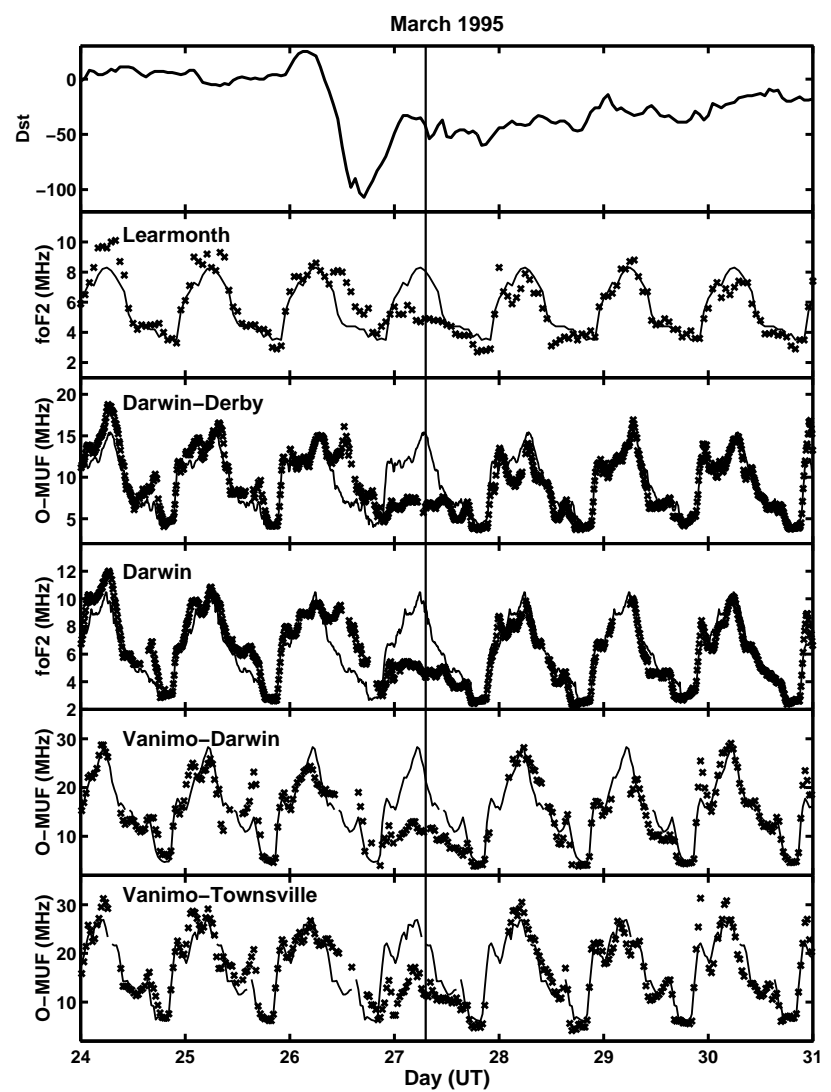

Fig. 3. $D_{s t}$, observed $f o \mathrm{~F} 2$ and and maximum oblique-path o-ray frequency values (crosses) and associated medians (line) for the period 24-31 March 1995. The TOPEX/Poseidon pass on the negative ionospheric storm day of 27 March is also shown (vertical line).

black. The corresponding TOPEX measurements of TEC are plotted in the lower part of Fig. 4 as a function of geographic latitude, with the negative storm-day pass shown in black. TEC profiles on the previous day are shown in green. The slow drift of the TOPEX orbit in the Sun-Earth frame produced a local time variation from 16:30 to 15:00 LT for the time of equatorial crossing over the eight days plotted.

Of immediate note in Fig. 4 is the great variability of the equatorial anomaly from day-to-day in both magnitude and location. Also evident is a tendency for the anomaly peaks to move further away from the magnetic equator with increasing magnitude. The satellite pass corresponding to the day of critical frequency depression, as measured by the ionosondes and displayed in Fig. 3, is characterized by the absence of the equatorial anomaly. At southern latitudes on this day, the TEC values are depressed well below the normal range of anomaly variation, whereas the northern latitude values remain within the non-storm day range but towards the lowest values at latitudes where the northern anomaly peak usually occurs. 

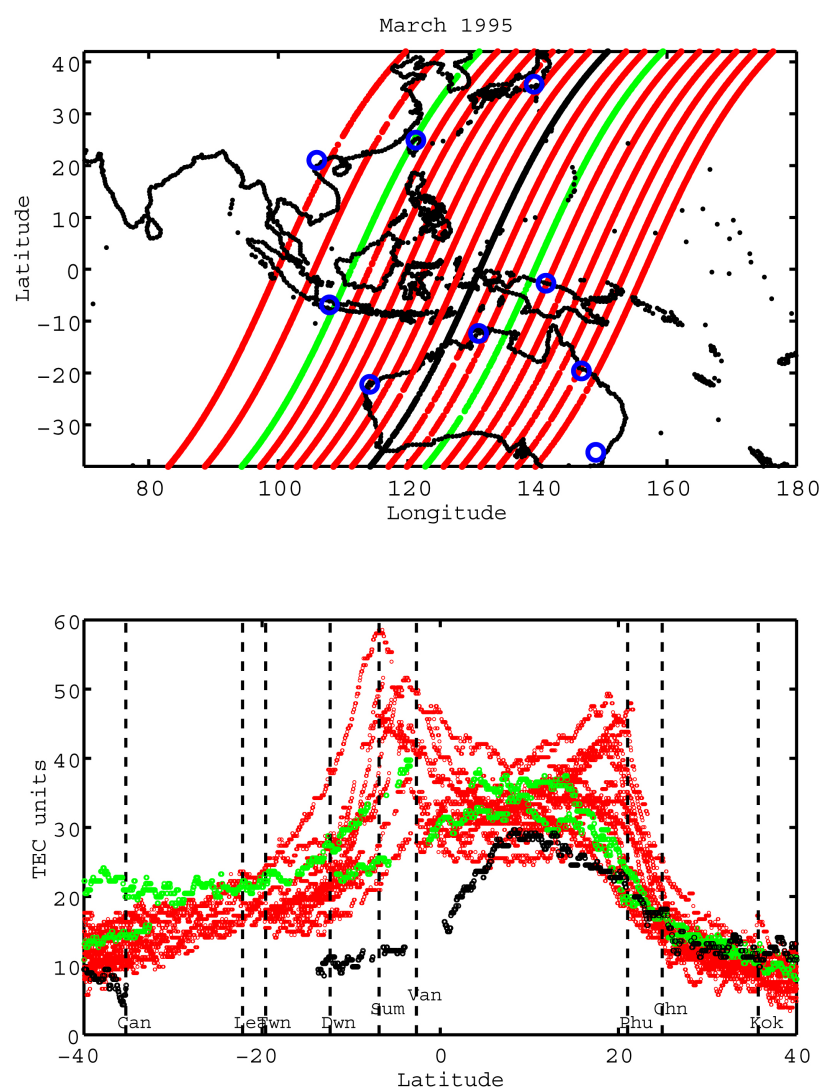

Fig. 4. TOPEX/Poseidon passes and corresponding TEC values observed between 16:30-14:05 LT over the period 24 March to 3 April 1995. The ionospheric negative storm day TOPEX pass on 27 March is shown in black and passes on the preceding day, 26 March, in green.

\subsection{Storm 2: 25 October 1997}

Figure 5 provides plots of $f o \mathrm{~F} 2$ or o-ray maximum frequency centered on the negative storm day, as observed at seven ionosonde reflection points ranging in longitude from New Guinea to Vietnam and in latitude from Northern Australia to Vietnam. Median values are also provided for comparison. A strong depression in maximum F2 frequencies is present throughout the daylight hours on 25 October 1997, extending into the early evening. The ionosondes at Sumedang and Vanimo were in operation for this event, thus extending the longitudinal and latitudinal range of observation on the southern side of the magnetic equator. Sumedang is of particular importance since it is normally lies near the peak of the southern anomaly crest, whereas Vanimo lies closer to the magnetic equator. The critical frequency of the ionosphere at Sumedang was strongly depressed as it was at the Cocos Island-Sumedang reflection point to the south and at Darwin. No obvious depression was observed at Vanimo for this event. In Fig. 5, the magnetic disturbance $D_{s t}$ index for the seven-day period is also shown for comparison with the ionosonde data. In this case, the magnetic storm is relatively weak, slow to recover and irregular in form. The relevant

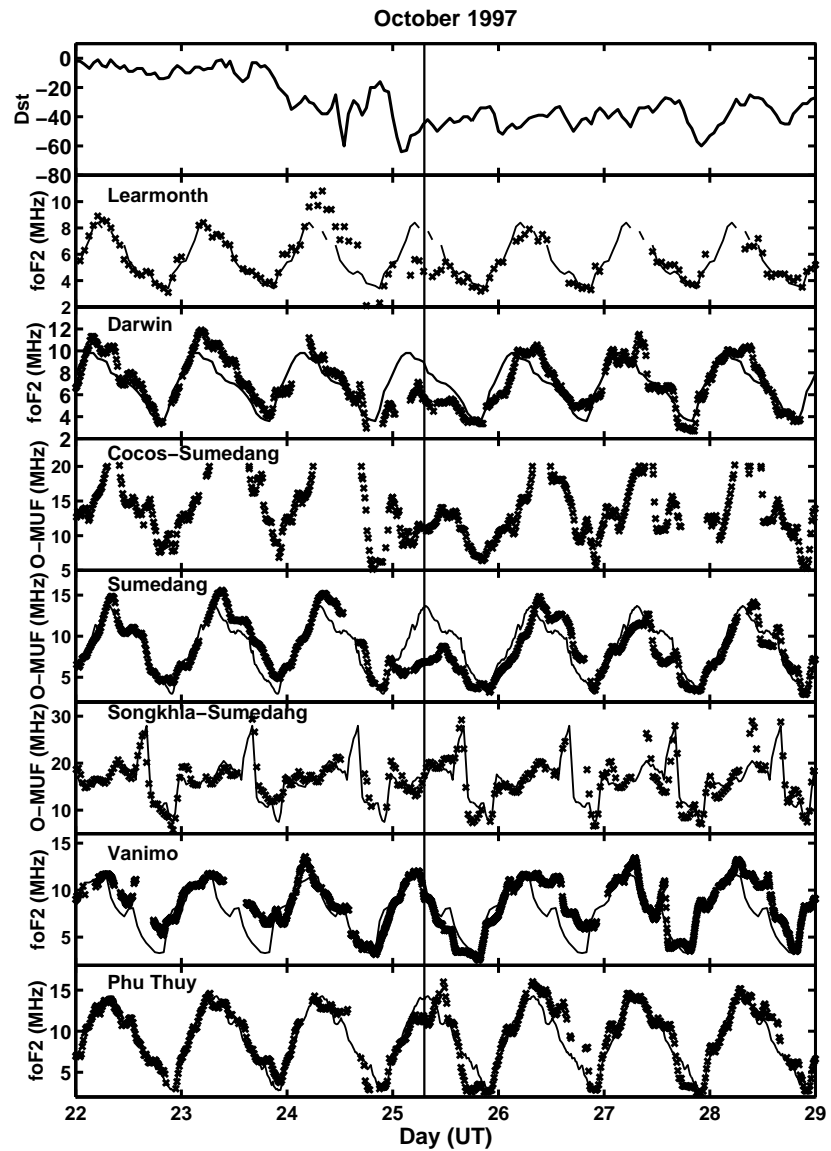

Fig. 5. $D_{s t}$, observed $f o \mathrm{~F} 2$ and maximum oblique-path o-ray frequency values (crosses) and associated medians (line) for the period 22-29 October 1997. The TOPEX/Poseidon pass on the negative ionospheric storm day of 25 October is also shown (vertical line).

start time is rather difficult to determine, although the first sign of magnetic disturbance is near dawn on the previous day. The vertical line running through Fig. 5 indicates the times of TOPEX/Poseidon satellite pass.

TOPEX passes and their corresponding TEC plots are shown in Fig. 6. The TOPEX pass for this event occurred at 15:22 LT on 25 October 1997 and is marked in black in the upper geographic plot and in the lower TEC plot of Fig. 6. The storm day pass lay between Sumedang and Darwin, which both showed a strong negative storm depression, whereas Vanimo, well to the east, showed no obvious effect. At the Northern Hemisphere site of Phu Thuy, the foF2 values were slightly depressed from the median at the time when the TEC profile showed the anomaly peaks to be absent. The TEC profile on the preceding day is in green.

The TOPEX passes shown in Fig. 6 cover the period from 21 to 31 October and range in local time from 16:10 to 14:10 LT. As before, the storm day pass is distinguished by a complete absence of any equatorial anomaly with Northern Hemispheric values lying at the bottom of the normal range of anomaly variation, whereas the Southern Hemispheric values fall well below the normal variation. The ionosonde at 

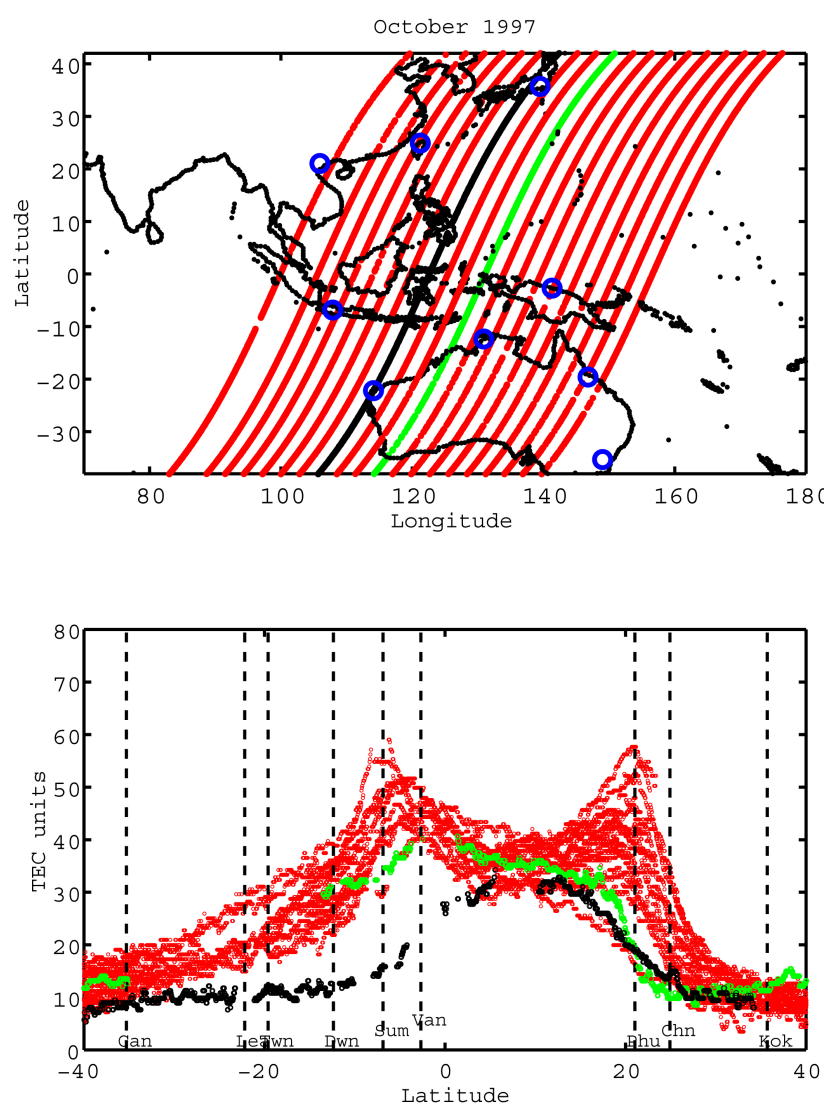

Fig. 6. TOPEX/Poseidon passes and corresponding TEC values observed between 16:10-14:09 LT) over the period 21-31 October 1997. The negative ionospheric storm day TOPEX pass on 25 October is shown in black and on the preceding day, 24 October, in green.

Phu Thuy shows a slight depression in $f o \mathrm{~F} 2$ from the median at this time that may be associated with the absence of the anomaly.

\subsection{Storm 3: 8 November 1997}

Figure 7 provides plots of $f o \mathrm{~F} 2$ or o-ray MOF centered on the storm day, as observed at seven ionosonde reflection points. Median values are also provided for comparison. A strong depression in maximum F2 frequencies is present at some sites throughout the daylight hours on 8 November 1997, extending into the early evening. The observations of this ionospheric storm cover the longitudinal range from $108^{\circ}$ to $141^{\circ}$ east and latitudinal range from $-22^{\circ}$ to $21^{\circ}$. The effects of this storm were seen at lower latitudes than for storms 1 and 2, with a significant depression in $f_{o} \mathrm{~F} 2$ occurring at Vanimo.

In Fig. 7, the magnetic disturbance $D_{s t}$ index for the seven-day period is shown for comparison with the ionosonde data. The negative ionospheric storm is seen to be associated with a magnetic storm commencing near sunrise on the previous day and reaching its peak near midday on that day. This storm has a particularly clear-cut rise and

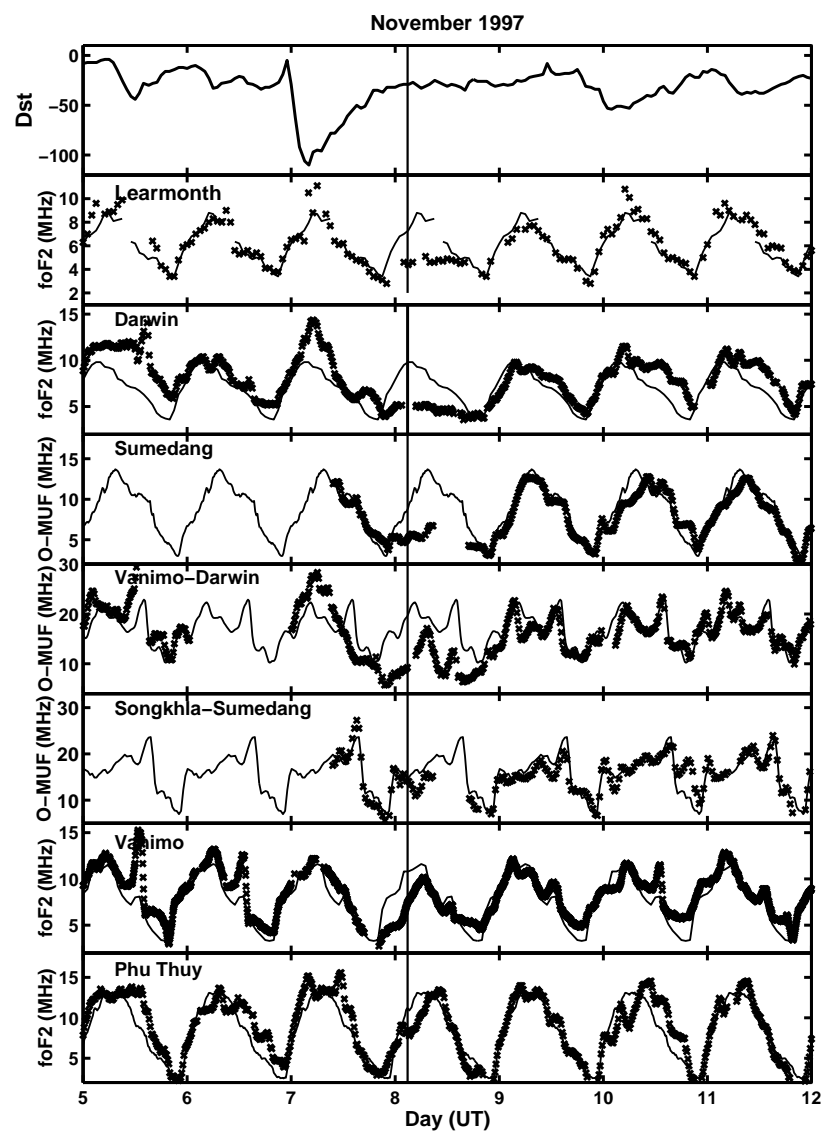

Fig. 7. $D_{s t}$, observed $f o \mathrm{~F} 2$ and maximum oblique-path o-ray frequency values (crosses) and associated medians (line) for the period 5-12 November 1997. The time of the TOPEX/Poseidon pass on the negative ionospheric storm day of 8 November is also shown (vertical line).

fall. The geomagnetic storm $D_{s t}$ values have recovered to normal levels on the day of ionospheric storm depression.

In the weeks prior to the geomagnetic storm, Vanimo was notable for a marked increase in ionospheric height in the post sunset period followed by a greater fall in height associated with a strong and sharp upward spike in $f o \mathrm{~F} 2$. This post-sunset spike can be seen in Fig. 7 on the 5 and 6 November. This characteristic pattern was destroyed on the night of 7 November, the night preceding the day of negative ionospheric storm depression, but had started to recover on the night of the 8th (negative storm day). The normal pattern was resumed on the following nights, though never again as strong.

The vertical line running through Fig. 7 indicates the time of the TOPEX/Poseidon satellite passes on the storm day.

TOPEX passes and their associated TEC measurements for a period centered on this storm are plotted in Fig. 8. Two successive TOPEX passes on the storm day fell within the longitudinal range for which ionosondes measurements were available. Equator crossings for these two passes were separated by $3152 \mathrm{~km}$ in space and $1.9 \mathrm{~h}$ in Universal Time but at essentially the same Local Time. Both passes showed a very 

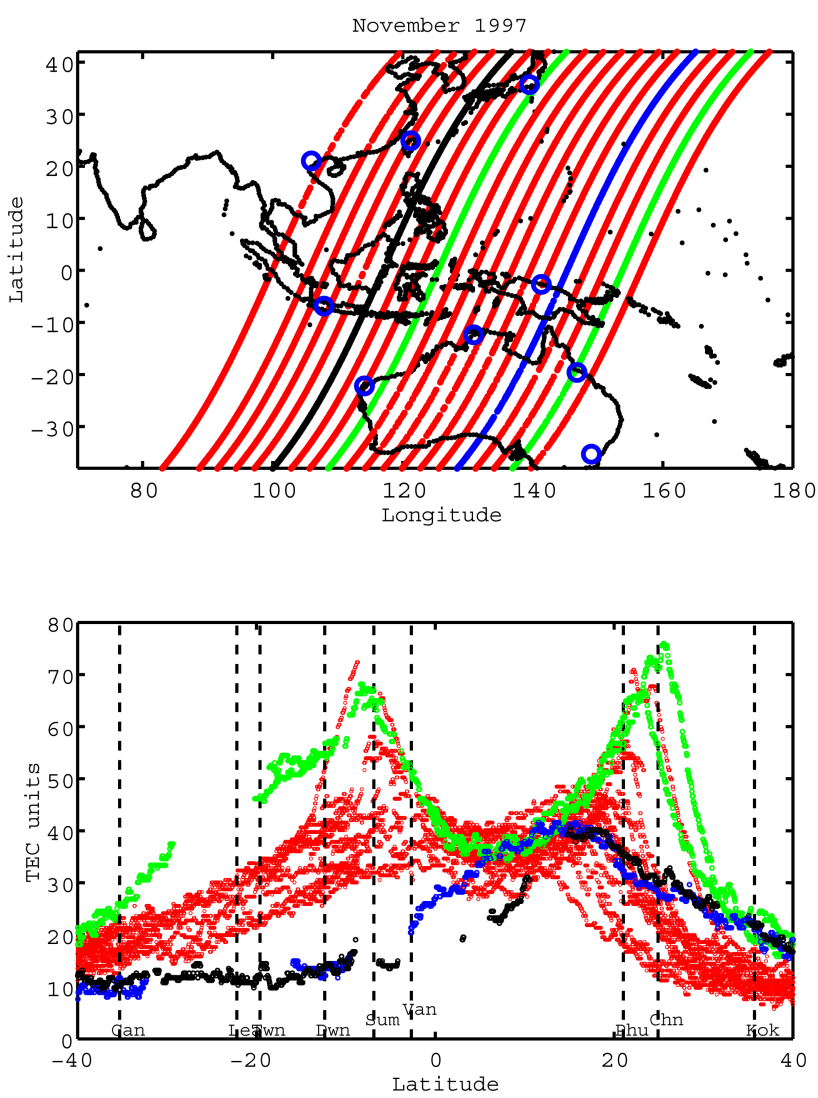

Fig. 8. TOPEX/Poseidon passes and corresponding TEC values observed between 14:08-12:08 LT over the period 31 October to 10 November 1997. Two negative ionospheric storm day passes on 8 November are shown in blue and black. Two passes on the previous day are shown in green showing a possible positive ionospheric storm effect.

strong storm bite-out in TEC on the southern side of the magnetic equator. The bite-out was greatest and extended further towards the magnetic equator on the second pass (04:44 UT, black TEC in Fig. 8), in comparison with the first (02:51 UT, blue TEC in Fig. 8), showing that significant changes could occur at the space and time separations involved. The TEC profiles on the previous day (green) show a strong anomaly and a positive increase at southern middle latitudes.

Figure 8 also shows, that far from being depressed, TEC values were at the higher end of the normal range at all northern latitudes beyond the anomaly region when negative storm conditions were present in the Southern Hemisphere. At the northern anomaly site of Phu Thuy, the $f o \mathrm{~F} 2$ values were less than the median at the time of the TEC profile which would seem to correspond to the absence of the anomaly peaks in the profile.

\section{Height measurements}

Negative ionospheric storm disturbances at middle and higher latitudes are characterized by an increase in virtual height associated with the decrease in F2 critical frequency.
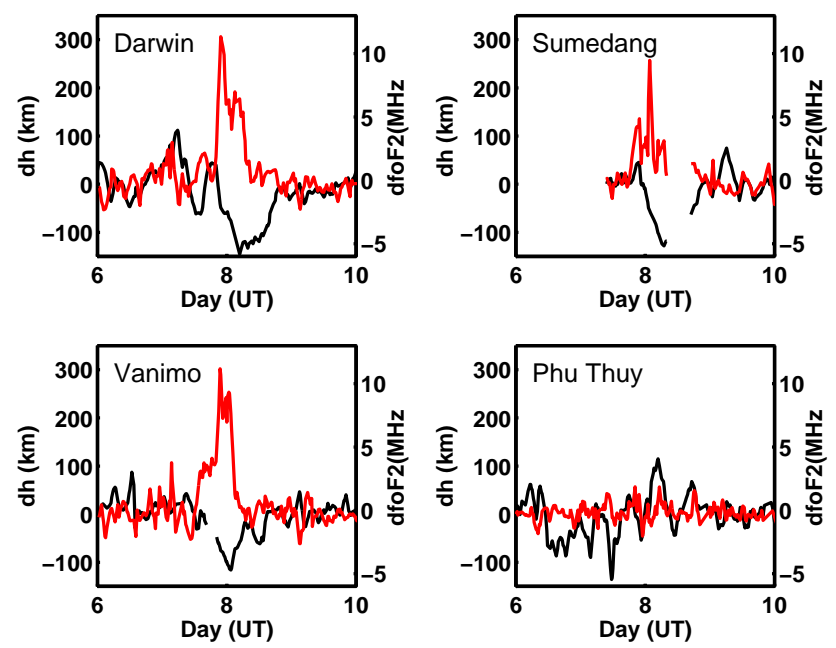

Fig. 9. Plotted differences in $f o \mathrm{~F} 2$ (black) and virtual height (red) from median values over the period 6-13 November 1997 (storm 3) from ionosondes at Darwin, Sumedang, Vanimo and Phu Thuy.

Measurements were made of the minimum virtual height of the F2 layer (i.e. $h^{\prime} \mathrm{F} 2$ in daytime and $h^{\prime} \mathrm{F}$ at night) for a seven-day period centered on the ionospheric storm of 8 November 1997. These values were subtracted from the corresponding median values of virtual height to give a measurement of height change $\delta \mathrm{h}$. Similarly, a measurement of $\delta \mathrm{f}$ was obtained from the median and observed values of $f o \mathrm{~F} 2$ previously shown for this storm in Fig. 7.

Values of $\delta \mathrm{h}$ and $\delta \mathrm{f}$ thus obtained are plotted in Fig. 9 for three sites that showed a significant depression in $f o F 2$ (Darwin, Sumedang and Vanimo) and one site where no major depression in $f \circ \mathrm{F} 2$ could be recognized (Phu Thuy). In all three sites where values of $f o \mathrm{~F} 2$ were seen to be depressed, there was an associated increase in virtual height. No variation in virtual height was observed at the northern hemispheric site of Phu Thuy over the period of the storm. The increase in virtual height associated with the ionospheric storm is seen to recover much more rapidly at all sites than the corresponding depression in $f o \mathrm{~F} 2$.

The increase in virtual height associated with negative ionospheric storms in daytime is mainly due to the nonlinear increase in time delay through the E and F1 layers which approaches infinity as the critical frequency of the F2 layer decreases to that of the F1 or less (the G condition). As well, TEC measurements of ionospheric slab thickness show an increase at such times which also increases the time delay. Thus, the increase in virtual height may have little geophysical meaning other than as a marker of a significant drop in $f_{o} \mathrm{~F} 2$. However, it does have important practical applications, since the range of oblique propagation is a function of virtual rather than real height. The increase in time delay may result in the F2 trace moving above the height range of the ionosonde, so that $f o \mathrm{~F} 2$ variations cannot be tracked accurately throughout a storm period. 


\section{Positive ionospheric storm effects?}

Negative ionospheric storms may also have associated positive storm effects, although the latter need to be strong or otherwise distinctive before they can be safely recognized against the normal range of $f o \mathrm{~F} 2$ variability. At ionosonde sites where a major depression in day values of $f o \mathrm{~F} 2$ occurs, positive storm effects have been reported on the preceding day (but still within the magnetic storm period). Some possible positive storm effects associated with the three storms discussed here are described below for the sake of completeness but their closer investigation lies outside the scope and data availability of the present paper.

Storm 1 showed a possible positive storm effect on the night before the negative ionospheric storm, with values of foF 2 well above the medians at all reflection points shown in Fig. 3. No such consistent increase across southern ionosonde sites was seen on nights preceding Storms 2 and 3 (Figs. 5 and 7). No night TOPEX/Poseidon passes in the necessary time interval were available to provide confirmation of this possible night event.

An increase in $f o \mathrm{~F} 2$ occurred in the daytime at Learmonth during storm 2 but was not unambiguously confirmed elsewhere or in the TEC profile.

Storm 3 showed a daytime positive increase in $f o \mathrm{~F} 2$ at sites south of Vanimo on 7 November 1997, the day preceding the negative storm and most notably at Vanimo-Darwin, Darwin and Learmonth (see Fig. 7). The TEC profiles on this day showed a very strong equatorial anomaly (at the upper end of the normal range) and a strong and positive increase in TEC extending from the anomaly into middle latitudes (shown in Fig. 8 by the green TEC passes). The TEC measurements thus confirm the ionosonde observations of an extended positive increase in ionospheric electron density. The TEC profiles (green) on 7 November 1997 are unusually consistent, considering their $3150 \mathrm{~km}$ separation in space (at the equator) and $1.92 \mathrm{~h}$ separation in universal time, indicating a large scale event.

\section{Discussion and conclusions}

The three negative ionospheric storms observed at lowlatitudes for which afternoon TOPEX/Poseidon TEC measurements were available were remarkably consistent in their behaviour. All occurred on the second daylight period after the commencement of the magnetic storm. The day of maximum ionospheric storm depression occurred during the recovery in $D_{s t}$ (as can be seen in Figs. 3, 5 and 7). This was particularly evident for the magnetic storms commencing on 26 March 1995 and 7 November 1997 which took a simple form of build up and recovery. All ionospheric storm days studied showed an absence of any equatorial anomaly development combined with a north-south asymmetry, such that the additional negative storm effects in both TEC and $f o \mathrm{~F} 2$ were confined to the Southern Hemisphere at all latitudes covered by the TOPEX/Poseidon satellite.
The TEC measurements show that the normal equatorial anomaly was highly variable in both magnitude and location. The absence of an equatorial anomaly at a particular longitude and time was not uncommon, even during magnetically undisturbed days. The distinguishing feature of the negative ionospheric storm days was the large bite-out in both TEC and $f \circ \mathrm{F} 2$ on the Southern Hemisphere side, resulting in values well below those seen on non-storm days. In contrast, the Northern Hemisphere TEC values were consistent with those seen on non-storm days when the equatorial anomaly was weak or absent and no clear negative storm effect was apparent in $f o \mathrm{~F} 2$ at the few northern ionosonde sites for which data was available. Thus, the absence of the equatorial anomaly was not itself the reason for the depressed values of $f o \mathrm{~F} 2$ seen by the southern ionosondes.

The results of this paper suggest that major negative ionospheric storms seen at low latitudes do not differ significantly from those observed at higher latitudes. The only distinguishing feature of the storms discussed here appears to be their penetration into the equatorial region and the effect on the equatorial anomaly. References typically describe negative ionospheric storms reaching no further equatorward than middle latitudes.

If the compositional change explanation of the negative storm is accepted, then both the hemispheric asymmetry and the yearly period of occurrence can be explained as a storm enhancement of the normal summer-to-winter wind given by the HWM93 model (Hedin, 1987). This enhanced wind carries compositional changes equatorward induced by additional auroral zone energy inputs associated with the magnetic storm, as discussed by Araujo-Pradere et al. (2002) in their development of an ionospheric storm model. The compositional change at $\mathrm{F} 2$ heights reaches lower latitudes during the night preceding the negative storm day, some $24 \mathrm{~h}$ or more after the magnetic storm commencement. The effect of the compositional change now present at low-latitudes becomes apparent as reduced F2 values of electron density associated with higher recombination rates are seen when the region rotates into daylight.

The change in direction of meridional wind sets in approximately at the equinoxes. This directional change, combined with the tendency of magnetic storm occurrence to peak at the equinoxes (Clúa de Gonzales, 2001), is consistent with the results shown in Fig. 2 for peak Southern Hemisphere negative ionospheric storm occurrence on the summer side of both equinoxes. Sixteen ionospheric storms examined by Sastri (1988) at Northern Hemisphere sites all occurred in the northern summer and equinoctial months in agreement with the seasonal dependence reported here and elsewhere (e.g. Essex et al., 1981; Titheridge and Buonsanto, 1988).

The compositional changes associated with the auroral zone magnetic storm heating and uplift are prevented from reaching low-latitudes in the northern winter hemisphere at this time by the northward direction of the prevailing wind (Forbes, 1989a, b; Prölss, 1993; Fuller-Rowell et al., 1996). This hemispheric difference between summer and winter will be emphasized at low latitudes because of the increased 
distance compositional changes must be carried. This compositional change is usually attributed to a reduction in the $\mathrm{O} / \mathrm{N}_{2}$ ratio, though other changes may also be involved. Satellite measurements of such a reduction associated with negative ionospheric storms have been given by Strickland et al. (2001) based on far ultraviolet imaging, though not at low latitudes. Mansilla (2003) has reported direct satellite measurements of compositional change in the neutral atmosphere at equatorial latitudes associated with geomagnetic storms but were unable to determine their origin or ionospheric effect. GPS measurements of TEC were recently used by Fedrizzi et al. (2001) to identify a north-south asymmetry in negative ionospheric storm effect.

A notable feature of the storms discussed in this paper is their apparent ability to switch off the normal occurrence of the equatorial anomaly. The same electric field which produces the equatorial anomaly also drives the equatorial electrojet current that flows mainly at $\mathrm{E}$ region heights along the magnetic equator. The electrojet is often taken as a surrogate for the electric field which is usually inaccessible to direct measurement. There is typically a delay of some hours between the electrojet and the anomaly reaching their maximum values. The cessation of the daytime equatorial anomaly in association with negative ionospheric storms has been inferred in the past (e.g. Sastri, 1988) by measuring the strength of the equatorial electrojet using magnetometers. However, the limited geographic coverage available from ionosonde data alone meant that the relative effects of the cessation of the anomaly and any major compositional change during daytime negative ionospheric storms could not unambiguously be distinguished at low latitudes. A recognition that the two effects can overlap at equatorial latitudes and their relative importance with regard to ionosonde observations between the effects of anomaly cessation and compositional change is made possible here by the availability of complete latitudinal profiles of TEC. The results of this paper suggest that, for the storms discussed in this paper, compositional changes appear to have been the main cause of the major depressions in $f o \mathrm{~F} 2$ seen by the ionosondes.

Whilst a relationship between the negative ionospheric storms observed at low latitude discussed here and a cessation of the equatorial anomaly seems clear, this is not the only source of equatorial anomaly variability. Changes in the east-west electric field as identified by a counter electrojet can alter (Forbes, 1989a) and suppress the development of an equatorial anomaly (Rastogi, 1999) whilst occurring under the quietest of geomagnetic conditions. The great day-today variability in anomaly strength outside periods of magnetic disturbance was one of the more obvious features of the TOPEX/Poseidon TEC profiles and represents a subject for investigation in its own right (Stening, 2003). Du and Stenning (1999) examine the origins of equatorial electric fields and possible sources of variability.

The ionospheric effect of the magnetic storm commencing on 7 November 1997 (discussed here as storm 3) was described by Huang and Foster (2001) as observed at the Millstone Hill incoherent scatter radar in North America. In con- trast to the results presented here, the main ionospheric effect consisted of a depression in electron density in daytime on the 7 November, the day preceding the low-latitude negative ionospheric storm effect at South-East Asian longitudes, with a partial recovery occurring on 8 November. Huang and Foster, 2001, show that an interplanetary shock impacted the Earth's magnetosphere at approximately 16:00 UT on 7 November, resulting in a sudden reduction in solar wind pressure. They propose two possible mechanisms for the negative ionospheric storm effect on this day. The first involves an outward expansion of the magnetosphere and consequent drop in ionospheric density produced by the decrease in solar wind pressure; the second is the effect of magnetospheric electric fields penetrating into the ionosphere. The explanations provided are in stark contrast to the delayed effect of compositional change reaching low-latitudes in the Southern Hemisphere proposed here. Given the complexity of ionospheric storm effects, these proposals may not necessarily be in conflict. However, such results do emphasize the need to combine a large range of ground and satellite equipments, simultaneously measuring magnetospheric, ionospheric, atmospheric composition, winds and electric fields over the surface of the Earth before a complete picture of any given magnetospheric/ionospheric storm can be obtained.

The equatorial anomaly on the days preceding the negative ionospheric storms, at times when both $f o \mathrm{~F} 2$ and TEC measurements were available, ranged widely from reduced to very strong.

The consistent absence of the equatorial anomaly on negative storm days would then seem to be associated in some way with the same atmospheric disturbance conditions which brought compositional changes to low-latitudes. The disturbed wind conditions at such times are often referred to as producing a disturbance dynamo with additional electric field effects produced over a large part of the Earth's surface.

Positive storm effects are most easily recognized when they combine a major increase and recovery in $f o \mathrm{~F} 2$ within a short period (hours). Examples of clear and positive storm effects, and negative storm effects in TEC are given by Essex et al. (1981). Possible positive storm effects were seen on the night before Storm 1. No relevant TEC passes were available at this time for comparison. A clear and positive increase in both TEC and $f o \mathrm{~F} 2$ was observed during the day preceding negative Storm 3. If these and other possible positive storm effects are indeed storm related, they indicate a great degree of variability from storm to storm, in contrast with the consistency of the negative storm effects.

It is clear from the TEC measurements that the positive enhancement of the diurnal $f \circ \mathrm{F} 2$ variation on 7 November 1997, seen at Vanimo-Darwin, Darwin and Learmonth, the day before ionospheric Storm 3, is due to the strong equatorial anomaly on this day and to an accompanying extension of high electron density values into the middle latitudes of the Southern Hemisphere. The increase in the TEC from the southern equatorial peak in Storm 3, which exceeds the normal range of TEC variability at middle latitudes, is consistent 
with the ionosonde observations and is the most persuasive evidence for a positive storm effect in this case. An explanation of the positive ionospheric storm effect would require a mechanism operating on this day as a result of geomagnetic storm conditions not present in Storms 1 and 2.

The effects on $f o \mathrm{~F} 2$ of the well-known post sunrise enhancement in vertical drift and its subsequent reversal (Fejer, 1997) were very strong at Vanimo in the weeks preceding Storm 3 (see observations in Sect. 4.3). A detailed examination of these effects and their disruption on the night preceding the day of ionospheric depression will be made elsewhere. These observations confirm that significant changes in low-latitude electric fields were occurring on the night before the negative component of ionospheric Storm 3.

Questions which arise from this paper include the relation between the negative ionospheric storm and its effect on the equatorial anomaly, as well as the source of the variability seen in the strength of the equatorial anomaly when no geomagnetic disturbance is present.

Acknowledgements. TOPEX/Poseidon data were obtained from the NASA Physical Oceanography Distributed Active Archive Center at the Jet Propulsion Laboratory, California Institute of Technology. We thank E. Essex and P. Wilkinson for help in obtaining data.

Topical Editor M. Lester thanks S. Watanabe and another referee for their help in evaluating this paper.

\section{References}

Araujo-Pradere, E. A., Fuller-Rowell, T. J., and Codrescu, M. V.: STORM: An empirical storm-time ionospheric correction model, 1. Model description, Radio Sci., 37, doi:10.1029/2001RS002467, 2002.

Buonsanto, M. J.: Ionospheric storms-a review, Sp.Sci.Rev., 88, 563-601, 1999.

Chen, H.-F: Analysis of the diurnal and semiannual variations of $D_{s t}$ index at different activity levels, J. Geophys. Res., 109, A03212, doi:10.1029/2003JA009981, 2004.

Clúa de Gonzales, A. L., Silbergleit V. M., Gonzalez, W. D., and Tsurutani, B. T.: Annual variation of geomagnetic activity, J. Atmosph. and Solar-Terr.Phys., 63, 367-374, 2001.

Danilov, A. D.: F2-region response to geomagnetic disturbances, J. Atmosph. and Solar-Terr. Phys., 63, 441-449, 2001.

Du, J. and Stening, R. J.: Simulating the ionospheric dynamoEquatorial electric fields, J. Atmosph. and Solar-Terr.Phys., 61, 925-940, 1999.

Essex, E. A., Mendillo, M., Schödel, J. P., Klobuchar, J. A., Da Rosa, A. V., Yeh, K. C., Fritz R. B., Hibberd, F. H., Kersley, L., Koster, J. R., Matsoukas, D. A., Nakata, Y., Roelofs, T. H.: A global response of the total electron content of the ionosphere to the magnetic storm of 17 and 18 June 1972, J. Atmos. Terr. Phys., 43, 293-306, 1981.

Fares Saba, M. M., Gonzalez W. D., and Clúa de Gonzales, A. L.: Relationships between the Ae, ap and $D_{s t}$ indices near solar minimum (1974) and at solar maximum (1979), Ann. Geophys., 15, 1265-1270, 1997.

Fedrizzi, M., de Paula, E. R, and Kantor, I. J.: Ionospheric Effects of the 26 August, 1998 Magnetic Storm over South America,
Proceedings of the International Beacon Satellite Symposium, Boston, MA, 4-6 June, 181-185, 2001.

Fejer, B. G.: The electrodynamics of the low-latitude ionosphere: recent results and future challenges, J. Atmosph. and Solar-Terr. Phys., 59, 1465-1482, 1997.

Forbes, J. M.: The equatorial electrojet, Rev. of Geophys. and Space Phys., 19, 469-504, 1989a.

Forbes, J. M.: Evidence for the equatorward penetration of electric fields, winds, and compositional effects in the Asian/Pacific sector during the 17-24 September, 1984, ETS interval, J. Geophys. Res., 94, 16 999-17 007, 1989b.

Fuller-Rowell, T. J., Codrescu, M. V., Rishbeth, H., Moffett, R. J., and Quegan, S.: On the seasonal response of the thermosphere and ionosphere to geomagnetic storms, J. Geophys. Res., 101, 2343-2353, 1996.

Fuller-Rowell, T. J. and Condrescu, M. V.: How does the thermosphere and ionosphere react to a geomagnetic storm?, Magnetic Storms, Geophys. Monogr. Ser., AGU, Washington, D.C., 98, 227-241, 1997.

Hedin, A. E.: MSIS-86 thermospheric model, J. Geophys. Res., 92, 4649-4662, 1987.

Huang, C. S. and Foster, J. C.: Variations of midlatitude ionospheric plasma density in response to an interplanetary shock, Geophys. Res. Lett., 28, 4425-4428, 2001.

Huang, T. X.: Major ionospheric storms during July-September 1982 at low latitudes in East Asia, J. Atmosph.Terr.Phys., 47, 1031-1036, 1985.

Huang, Y.-N. and Chen, K.: Ionospheric disturbances at the equatorial anomaly crest region during the March 1989 magnetic storms, J. Geophys. Res., 96, 13 953-13 965, 1991.

Lyatsky, W. and Tan, A.: Latitudinal effect in semiannual variation of geomagnetic activity, J. Geophys. Res., 108, doi:10.1029/2002JA009467, 2003.

Ma, S. Y., Xu, L. and Yeh, K. C.: A study of ionospheric electron density deviations during two great storms, J. Atmosph. Terr. Phys., 57, 1037-1043, 1995.

Mansilla, G. A.: Disturbances at F2-region heights of equatorial anomaly during geomagnetic storms, J. Atmosph. and SolarTerr.Phys., 65, 987-996, 2003.

Mikhailov, A. V., Forster M., and Leschinskaya, T. L.: Disturbed vertical $\boldsymbol{E} \times \boldsymbol{B}$ plasma drifts in the equatorial F2 region at solar minimum deduced from observed $\mathrm{NmF} 2$ and $\mathrm{hmF} 2$ variations, Ann. Geophys., 14, 733-743, 1996.

Prölss, G. W.: On explaining the local time variation of ionospheric storm effects, Ann. Geophys., 11, 1-9, 1993.

Prölss, G. W.: Magnetic storm associated perturbations of the upper atmosphere, Magnetic Storms, Geophys. Monogr. Ser., AGU, Washington, D.C., 98, 227-241, 1997.

Rastogi, R. G.: Morphological aspects of a new type of counter electrojet event, Ann. Geophys., 17, 210-219, 1999.

Richmond, A. D. and Lu, G.: Upper-atmospheric effects of magnetic storms: a brief tutorial, J. Atmosph. and Solar-Terr. Phys., 62, 1115-1127, 2000.

Rishbeth, H.: How the hemispheric circulation affects the ionospheric F2 layer, J. Atmosph. and Solar-Terr. Phys., 60, 1385$1402,1998$.

Rishbeth, H.: The equatorial F-layer: progress and puzzles, Ann. Geophys., 18, 730-739, 2000.

Sastri, J. H.: Equatorial electric fields of ionospheric disturbance dynamo origin, Ann. Geophys., 6, 635-642, 1988.

Stening, R. J.: Space weather in the equatorial ionosphere, Space Sci. Rev., 107, 263-271, 2003. 
Strickland, D. J., Daniell, R. E., and Craven, J. D.: Negative ionospheric storm coincident with DE 1-observed to thermospheric disturbance on October 14, 1981, J. Geophys. Res., 106, 21 049$21062,2001$.

Szuszczewiez, E. P., Lester, M., Wilkinson, P., Blanchard, P., Abdu, M., Hanbaba, R., Igarashi, K., Pulinets, S., and Reddy, B. M.: A Comparative study of global ionospheric responses to intense magnetic storm condition, J. Geophys. Res., 103, 11 665-11 684, 1998.
Tanaka, T.: Severe ionospheric disturbances caused by the sudden response of evening subequatorial ionospheres to geomagnetic storms, J. Geophys. Res., 86, 11 335-11 349, 1981.

Titheridge, J. E. and Buonsanto, M. J.: A comparison of Northern and Southern Hemisphere TEC storm behaviour, J. Atmosph. and Solar-Terr. Phys , 50, 763-780, 1988.

Wilkinson, P. J.: Predictability of ionospheric variations for quiet and disturbed conditions, J. Atmosph. Terr. Phys., 57, 1469$1481,1995$. 